ual, and it is to be defined and investigated by these methods: 1 . The examinaation of self as heretofore carried on. 2 . The examination of allied phenomena in the healthy condition of other minds, bringing them into comparison with our own; and, 3 . The examination of minds more or less diseased in the direction of their personality. He lays especial stress on the last mentioned, referring to cases where the sense of personality has been partly or wholly lost. The problems of unconscious cerebration, sublimital consciousness, and the like, must also receive due attention.

University of Pennsylyania.

\section{G. Brinton.}

\section{SCIENTIFIC NOTES AND NEWS.}

THE INTERNATIONAL CATALOGUE OF SCIENCE.

THE International Conference to consider the preparation of a catalogue of scientific literature by international coöperation will be held at the rooms of the Royal Society, London, beginning on Tuesday, July 14th.

The committee of the Royal Society suggests provisionally that the author and subject catalogue shall be restricted in the first instance to branches of pure science, such as mathematics, astronomy, physics, chemistry, geology, zoölogy, botany, physiology and anthropology, to the exclusion of applied science, such as engineering, medicine and the like, but that all definite contributions to pure science shall be thoroughly indexed, whether occurring in books, memoirs, etc., treating of pure science or in those devoted to applied or practical science.

The committee also recommends that there shall be a first issue of authors' titles, subjectmatter, etc., in the form of slips or cards, which shall be distributed as speedily and as frequently as possible to subscribers, and that a further issue in book form shall take place at such intervals as shall be determined on, parts corresponding to the several sciences, being, if found desirable, published separately.

It is recommended that a central bureau shall be established under the control of an international council having authority over any under- taking which may be allotted to particular countries, institutions or persons. The cost of the catalogue, in so far as it is not met by sales, should be provided for by means of a guarantee fund subscribed by governments, learned societies, institutions and individuals throughout the world, and it is estimated that the annual sum thus to be secured should be approximately $\$ 50,000$.

The conference will have to take into consideration where the bureau shall be placed, how the international council shall be appointed and organized, what language or languages shall be used and what system of classification shall be adopted. It is suggested that the decimal system of Dewey may be so amended as to be worthy of adoption.

As already stated in this journal, the delegates to the conference from the United States are Dr. John S. Billings and Prof. Simon Newcomb.

\section{EXHIBITION OF THE NEW YORK MICROSCOPICAL SOCIETY.}

THE Seventeenth Annual Exhibition of the New York Microscopical Society took place at the American Museum of Natural History on Tuesday evening, April 14th. The attendance steadily increasing from year to year has been a true indication of the value of this exhibition in what is usually spoken of as 'popularizing science.' The indiscriminate study of natural science often works more harm than good, especially if it be acquired through desultory and misdirected reading. Personal observation insures the safest and most lasting knowledge of Nature's acts and works. If this principle has been inculcated into the non-scientific portion of the audience, one purpose of the exhibition will have been accomplished. Persons more directly concerned and interested in scientific work also found enough to attract their attention.

The catalogue of seventy exhibits included many specimens of chemical crystals and minerals ; various forms of pond life; the mouth parts of several insects, with specimens of their destructive borings in wood and other substances ; drug plants and preparations of these ; microscopical tests for the detection of quinine, 